\title{
Health inequality in the Russian Federation: An examination of the changes in concentration and achievement indices from 1994 to 2013
}

\author{
Pavitra Paul ${ }^{*}$ (D) and Hannu Valtonen
}

\begin{abstract}
Background: To assess and quantify the magnitude of health inequalities ascribed to socioeconomic strata from 1994 to 2013 in the Russian Federation.

Methods: A balanced sample of 1,496 adult individuals extracted from the 1994 wave of the Russian Longitudinal Monitoring Survey (RLMS) is followed for stated self-perceived health status until 2013. The socioeconomic strata (SES) index is constructed with a set of variables (adult equivalent household income, ownership of assets and living conditions) by applying principal component analysis (PCA). We use a regression-based concentration index to measure differences in self-perceived health status. Finally, we examine the degree of aversion to inequalities in self-perceived health status between the worse-off and the better-off with the achievement index.
\end{abstract}

Results: By 2013, the mean standardized self-perceived health status has improved by $4.6 \%$ compared to 1994. The absolute size of Concentration Index (Cl) for non - standardized self-perceived health status is reduced by $44.27 \%$ from 1994 to 2013. No systematic trend emerges in the evolution of Cl for self-perceived health status of the Russians over the 19 year period. However, avoidable inequalities in self-perceived health status of the Russian population is reduced by almost $60 \%$ over the two decades (1994-2013).

Conclusion: SES, as defined with objective indicators, shows little consistency in association with self-perceived health status in the Russian Federation. This study highlights the need for future research that considers the context of stated self-perceived health status in the realm of subjective socioeconomic status (SSS).

Keywords: Achievement, Aversion, Concentration, Distributionally-sensitive, Health inequalities, Positive-externality, Self-perceived, Subjective socioeconomic status, Russia

\section{Background}

The collapse of the Soviet Union resulted in large fluctuations in household resources and increased uncertainty for the Russian people. Much academic research has explored the socioeconomic and political ramifications of this transition to a mainstream market economy. The importance of health in times of rapid change in the economy has been highlighted in economic development literature [1,2]. Preston [3] concludes that factors other than individual income play a powerful role in the

\footnotetext{
* Correspondence: pavitra.paul@uef.fi

Department of Health and Social Management, Faculty of Social Sciences and Business Studies, University of Eastern Finland, Kuopio 70211, Finland
}

determinants of health conditions that are often associated with poverty. This reinforces the idea that individual incomes in isolation from the community in which people are located do not immediately reflect health status. Neighbourhood affluence is a more powerful predictor of health status than poverty, above and beyond individual demographic background, socioeconomic status, and health behaviours [4]. An empirical study using Spanish Living Conditions Survey datasets (2005-2008) revealed that the relationship between health and income operates through comparison information with respect to societal peers; conversely, material deprivation in terms of financial difficulties, basic necessities, and 
housing conditions exerts a direct effect on one's selfperceived health status [5].

Vella [6] has reported the prevalence of a considerably high share of dissatisfaction with self-perceived health status among the respondents of the Russian Longitudinal Monitoring Survey, 1993, and Cockerham [7] has found no relationship between income and self-perceived health status among the respondents of the Russian Longitudinal Monitoring Survey, 1995. Another cross-sectional study by Cockerham et al. [8] reported a similar relationship between income and self-perceived health status among the respondents of the Russian Longitudinal Monitoring Survey, 1998. Further, the Russian Longitudinal Monitoring Survey, 1998 reflected a strong negative correlation between the health status of the individual and the desire to return to the former Soviet regime - a reflection of dissatisfaction with the economic and social conditions of the time [8]. A panel data frame study using Russian Longitudinal Monitoring Survey (1994-2000) datasets showed little effect of income on self-perceived health status when the possibilities of reverse causation and incidental association between income and health were accounted for (Stepanyan A. Is Economic Transition a Health Hazard? Self-perceived Health and Income in Russia: 1994-2000. Unpublished working paper 2002). However, a longitudinal study (Jensen RT. Job Security, Stress and Health: Evidence From Russian Privatization. Unpublished working paper 2005) using Russian Longitudinal Monitoring Survey datasets (1992-1994) suggested a correlation between negative health consequences with concern about the likelihood of job loss.

Kraus et al. [9] have shown that chronically experienced negative affects (higher temperamental sensitivity to negative stimuli resulting in feelings of fear, anxiety, depression, guilt, and self-dissatisfaction) explains rather than confounds the link between socioeconomic strata and self-perceived health. The systematic review study of Ostrove and Adler [10] suggests that the pathway from socioeconomic strata to health is through exposure to different environments and adaptations to these environments. Environmental demands and supports shape individual responses to self-perceived health. Unemployment and inflation have often been considered two of the most robust determinants of individual happiness, with unemployment typically having a stronger negative impact than inflation. Eggers et al. [11] found that in the Russian Federation, higher unemployment rates lead to more happiness, as people tend to revise their expectations upwards when their neighbours are suffering. Rodríguez-Pose and Maslauskaite [12] argued that citizens are quite tolerant of interpersonal inequality, and as the economy is still dynamic, open and volatile, the influence of macroeconomic factors on happiness varies substantially over time; therefore cross-sectional analysis cannot provide any robust conclusions.

An empirical study (using eight waves of the European Community Household Panel) reflects a larger effect of activity status on self-perceived health than the effect of income. Inactivity is associated with the largest absolute effect, in part, among individuals claiming disability allowances due to ill health [13]. A cross-sectional study [14] on the evolution of health inequalities in Switzerland found no systematic trend in the changes with the measure of health inequalities between 1982 and 2002.

The ecosocial theory of health distribution, introduced by Krieger in 1994 [15] postulates that (1) population health and health inequities must be analysed in a societal, historical, and ecological context, and (2) neither the forms of social inequality nor their associations with health status are "fixed", but are instead historically contingent. The relationship between socioeconomic strata (SES) and health changes with age, since the mediators of SES act differently in different stages of the life course. Health in later life is the result of multiple social and biological processes whose effects interact and accumulate over time [16-18].

The microeconomic perspective assesses health costs (or the economic benefits of good health) at the individual or household level. Macroeconomic consequences are viewed from the level of the national economy, generally considering the level of population health that retards a country's economic growth. The realization of the economic objectives with a concurrent reduction of poverty (more relevant for transitional economies) necessitates evidence-informed policy development for investment in health. The micro perspective is also specifically important for individuals and households, as freedom from ill health adds different dimensions of economic well-being to individuals and households. Further, the concern for poverty and inequality recognizes that in health status societal averages typically disguise as much as they reveal, therefore, the interest is not in health status that prevail in society as a whole but in health status of different socioeconomic groups [19].

This paper investigates how the difference in the selfperceived health status of Russians has evolved in the context of the transition to a mainstream market economy, and following the approach of Wagstaff, Makinen et al. and Castro-Leal et al. [20-22], this study examines the trend in the distribution of such difference across the socioeconomic strata of the population from 1994 to 2013. Our data is unique in the sense that we follow the same individuals over an 18-year period.

\section{Methods}

The data for this study are from the 1994-2013 waves of the Russian Longitudinal Monitoring Survey (RLMS). RLMS (http://www.cpc.unc.edu/rlms) is an on-going longitudinal household survey of the Russian Federation. The survey was designed to be representative of the Russian population in the early 1990s. The survey contains an array of information on the economic, social, 
demographic, and health characteristics of respondents, their households, and the environments in which they live. An initial representative sample of dwellings was drawn in 1992 and surveyed every six months until 1994 (phase 1). A second more broadly drawn representative sample (phase 2) replaced the initial sample in 1994 and is being followed annually since then. For cost reasons, RLMS does not attempt to follow individuals or households who move from their original sample dwelling units (attempts are made to follow individuals and households that move locally); instead, any new household member or household living at that dwelling is included in the sample in each wave. Thus, the RLMS sample remains representative of the underlying population if new residents can be considered exchangeable with those that moved. ${ }^{1}$

The RLMS data sets contain post-stratification weights, that is, weights that adjust not only for design factors but also for deviations from census characteristics. Variation in individual weights reflects the geographic effects for households as well as differentials due to post-stratification of the sample by major geographic region, age, and gender. The multivariate distribution of the sample by gender, age, and urban/rural location compared quite well with the corresponding multivariate distribution of the 1989 census (http://www.cpc.unc. edu/rlms).

From this unbalanced sample, we chose RLMS participants who had been included in all 18 waves. Thus, after balancing the panel, we followed 1,496 individuals (Table 1), henceforth to be read as study sample. We explored the study sample selection (i.e., difference in characteristics of respondents between the extracted individual and RLMS - 1994 datasets) with the binary (study sample $=1$, RLMS -1994 datasets $=0$ ) using logit model. Hence, with the long (19 year) follow-up of the individuals, we have controlled the variations attributed to the sampling population per se. The use of more than one observation facilitates causal inference in situations where inferring causality becomes very hard if only a single cross section are used and the panel nature of the data allows for the unobserved effect to be correlated with the explanatory variables - thus, ensures a better control for the unobserved effects of the variables [23].

Our dependent variable for the analysis is selfperceived (self-perceived) health (SAH). Individuals were asked, "How would you evaluate your health?" and the response was recorded on a five-point Likert scale with the answers "very good", "good", "average - not good but not bad", "bad", and "very bad". SAH variables have been widely used in literatures [24-27] that analyse the socioeconomic health gradient.

We constructed an SES index by applying principal component analysis (PCA) using a set of variables (adult equivalent household income, ownership of assets, living conditions, and other indicators of material affluence, i.e., having savings and growing crops) with a KaiserMeyer-Olkin score of 0.80 and above. With the RLMS 1994, PCA resulted in two principal components (PC), first PC accounting for $29 \%$ of the total variance captured in seven items (adult equivalent household income, country house, own house, additional apartment, central heating, hot water supply and use of cooking gas), while the second PC accounted for $15 \%$, captured in four items (adult equivalent household income, country house, own house and additional apartment). With the data sub-set (study sample), the first PC accounted for $33 \%$ of the total variance captured in seven items (adult equivalent household income, country house, own house, additional apartment, central heating, hot water supply and use of cooking gas), while the second PC accounted for $15 \%$, captured in four items (adult equivalent household income, country house, additional apartment, central heating). The income variable represented the sum of incomes from all sources for the household deflated to the value of June 1992. We calibrated the household income as per adult equivalent using the modified OECD $\mathrm{scale}^{2}$ for our analyses. We measured inequality in income by the Gini index. ${ }^{3}$

We standardized $[28,29]$ the self-perceived health status by age, gender, and diagnosed chronic diseases, applying the indirect method of standardization. ${ }^{4}$ We estimated the correlation of the confounding variables (age, gender, and diagnosed chronic diseases) with selfperceived health status conditional on non-confounding variables (region, settlement of residence, and SES). This regression-based approach (Eqn. 1) "corrects" the actual distribution of the self-perceived health status by comparing it with the distribution that would be observed if all individuals in the group had their own age and gender characteristics but the same mean age and gender effect as the entire population.

$$
y_{i}=\alpha+\sum_{j} \beta_{j} x_{j i}+\sum_{k} \gamma_{k} z_{k i}+\epsilon_{i}
$$

where, $y_{i}$ is self-perceived health status; $i$ denotes the individual; and $\alpha, \beta$, and $\gamma$ are parameter vectors. The $\mathrm{x}_{j}$ are confounding variables (age, gender, and diagnosed chronic diseases), which we want to standardize, and the $z_{k}$ are non-confounding variables (region, settlement of residence, and SES), which we do not want to standardize but to control for in order to estimate partial correlations with the confounding variables. The Newey-West ${ }^{5}$ estimator estimates $\left(\hat{\alpha}, \hat{\beta}_{j}, \hat{\gamma}_{k}\right)$ the individual values of the confounding variables $\left(\mathrm{x}_{j i}\right)$, and sample means of the non-confounding variables $\left(\bar{z}_{k}\right)$ are then used to obtain the predicted, or "x-expected," values of the self-perceived health status $\hat{y}_{i}^{x}$. 
Table 1 Descriptive statistics

\begin{tabular}{|c|c|c|c|c|}
\hline Variables & $2013(N=1496)$ & $1994(N=1496)$ & RLMS data - $1994(N=8893)$ & $\begin{array}{l}\text { Test of independence (between the } \\
\text { datasets - } 1994 \text { and extracted sample) }\end{array}$ \\
\hline \multicolumn{5}{|l|}{ Age group (in years) } \\
\hline$<30$ & & 24.53 & 28.8 & \\
\hline $31-44$ & & 37.83 & 25.97 & \\
\hline $45-60$ & & 29.75 & 21.7 & \\
\hline $61-74$ & & 7.69 & 17.32 & \\
\hline \multirow[t]{2}{*}{$75+$} & & 0.2 & 6.21 & \\
\hline & & & & $x^{2},[p$-value $=0.000]$ \\
\hline Age group (in years) by gender & & Female (\%) & Female (\%) & \\
\hline$<30$ & & 60.76 & 52.18 & \\
\hline $31-44$ & & 61.84 & 52.75 & \\
\hline $45-60$ & & 71.69 & 56.15 & \\
\hline $61-74$ & & 70.43 & 61.92 & \\
\hline $75+$ & & 100.0 & 78.35 & \\
\hline \multirow[t]{2}{*}{ Total } & & 65.24 & 56.14 & \\
\hline & & & & $x^{2},[p$-value $=0.000]$ \\
\hline \multicolumn{5}{|l|}{ Settlement of residence (\%) } \\
\hline Urban & 51.27 & 52.11 & 69.32 & $x^{2},[p$-value $=0.000]$ \\
\hline \multicolumn{5}{|c|}{ Self-perceived (self-assessed) health (\%) } \\
\hline Very Good & 0.61 & 1.54 & 1.93 & \\
\hline Good & 17.26 & 23.04 & 23.4 & \\
\hline Average & 57.13 & 62.89 & 54.44 & \\
\hline Bad & 21.94 & 10.98 & 16.52 & \\
\hline \multirow[t]{2}{*}{ Very bad } & 3.06 & 1.54 & 3.7 & \\
\hline & & & & $x^{2},[p$-value $=0.000]$ \\
\hline Diagnosed Chronic disease ${ }^{a}(\%)$ & 16.38 & 7.29 & 8.46 & $x^{2},[p$-value $=0.000]$ \\
\hline Satisfaction with life $(\%)$ & 72.47 & 31.18 & 35.40 & $x^{2},[p$-value $=0.000]$ \\
\hline
\end{tabular}

Adult equivalent household income (Rb. per month inflation adjusted at the level of June 1992)

$\begin{array}{llll}\text { Mean } & 7610 & 4110 & 5410 \\ \text { Median } & 6880 & 3220 & 3760\end{array}$

t-test $[p$-value $=0.000]$

Ownership of assets (\%)

$\begin{array}{lrc}\text { Tractor } & 4.88 & 2.08 \\ \text { Motorvehicle } & 25.30 & 26.54 \\ \text { Country house (dacha) } & 18.65 & 12.03 \\ \text { Own house } & 93.65 & 83.87 \\ \text { Addl. Appartment } & 5.08 & 2.61\end{array}$

1.26

25.46

13.87

87.88

4.36

Living condition (\% of respondents with access to public services utilities)

$\begin{array}{lll}\text { Central heating } & 52.44 & 55.78 \\ \text { Hot water supply } & 47.86 & 42.63 \\ \text { Cooking gas } & 71.05 & 64.03 \\ \text { Central garbage disposal } & 55.72 & 52.16\end{array}$

Other indicators of economic status (\%) 
Table 1 Descriptive statistics (Continued)

\begin{tabular}{|c|c|c|c|c|}
\hline $\begin{array}{l}\text { Grow crops (incl. growing vegetables } \\
\text { in house lawns and rented lands) }\end{array}$ & 92.86 & 98.5 & 96.29 & $x^{2},[p$-value $=0.000]$ \\
\hline Having savings ${ }^{c}$ & 18.13 & 8.63 & 10.79 & $x^{2},[p$-value $=0.003]$ \\
\hline \multicolumn{5}{|l|}{ SES quintile ${ }^{d}(\%)$} \\
\hline Poorest & 20.10 & 20.06 & 20.06 & \\
\hline 2nd poorest & 19.94 & 20.05 & 19.97 & \\
\hline Middle & 20.01 & 20.06 & 19.99 & \\
\hline 2nd richest & 20.01 & 20.05 & 20.06 & \\
\hline Richest & 19.94 & 19.78 & 19.92 & \\
\hline
\end{tabular}

Diagnosed with and or suffered from Diabetes, heart attack, stroke and anaemia

${ }^{b}$ Response to the question: 'to what extent are you satisfied with your life in general at the present time? '[ 1 = fully satisfied, rather satisfied and both yes and no; $0=$ less than satisfied and not at all satisfied]

'Response to the question: 'did your family in the last 30 days save any money?'

${ }^{\mathrm{d}}$ Distribution of respondents in quintiles based the constructed socioeconomic strata

$$
\hat{y}_{i}^{x}=\hat{\alpha}+\sum_{j} \hat{\beta}_{j} x_{j i}+\sum_{k} \hat{\gamma}_{k} \bar{z}_{k}
$$

Estimates of indirectly standardized self-perceived health:

$$
\hat{Y}_{i}^{I S}=Y_{i}-\hat{Y}_{i}^{X}+\bar{Y}
$$

where,

- $\hat{Y}_{i}^{I S}=$ indirectly standardized, self-perceived health status

- $Y_{i}=$ actual health

- $\hat{Y}_{i}^{X}=x$-expected health

- $\bar{Y}=$ overall sample mean

In the next step, following the principles of previous analyses [30, 31], we dichotomized the five-scaled measure into a binary variable [32], "self-perceived health" $(1=$ good, i.e., responded as "very good", "good", and $0=$ not good, i.e., responded as "average", "bad" and "very bad").

The conventional regression-based statistical methods report the magnitude and the direction of association between socioeconomic position and the health status of the individual but ignores the possibility of variance in the effect of explanatory variables across distribution. Further, such traditional methods cannot reflect the extent of health disparity across socioeconomic strata of the population and thus do not allow for comparison over time [30]. Therefore, we used the health concentration index (Appendix: A) as our measure of SES-related inequality. The concentration index (CI) becomes positive if health (i.e., self-perceived health status) is concentrated amongst the better-off, negative if health (i.e., self-perceived health status) is concentrated amongst the worse-off, and zero if no inequality is observed. Thus, CI can also be interpreted as the slope of a line passing through the heads of an army of people, ranked by their SES, with the height for each individual proportionate to the value of his/her self-perceived health status, expressed as a fraction of the mean for the group.

Finally, with the achievement index ${ }^{6}$ (Appendix: B), we measured the average level of health and the inequality in health between the worse-off and the better-off. Achievement is the weighted average of the health (selfperceived) level of the individuals (members) in the study (community) where higher weights are attached to worse-off than to better-off (The mean is clearly not appropriate, since it weights everyone's health, here, selfperceived health status equally, irrespective of how poor they are). Thus, achievement index is distributionally sensitive measure of population health. CI captures the extent to which ill health is concentrated amongst the worse-off. Achievement index indicates the degree of aversion to inequalities in health between the worse-off and the better-off [33].

\section{Ethics}

This study uses secondary data collected from perpetual surveys. The datasets are anonymously coded with no individual identification identifiable by the user. The user has explicit authorization to use the datasets made available for analysis.

\section{Results}

Table 1 exhibits that the study sample (the balanced panel) of this study was represented by a greater number of females. In addition, the proportion of the 31-60 age group was relatively higher and the proportion of the over 60 age group was substantially lower in the balanced panel. The distribution of respondents (study sample in the balanced panel) with self-perceived health status as good and not good was similar between study sample and RLMS-1994 datasets. The inflation adjusted adult equivalent household income (mean and median) was smaller for the respondents in the study sample and also the proportion of respondents with access to public 
service utilities was smaller in the study sample when compared with RLMS - 1994 datasets. However, the rural respondents and the respondents with having own tractor was higher in the study sample. Though the distribution of respondents by SES quintile (constructed) was almost similar between study sample and RLMS 1994 datasets, the test of independence between the study sample and RLMS - 1994 datasets were significant for all the variables used in the study except for such test of respondents with having motor vehicle.

The descriptive statistics (Table 1) reflected a decline (from good to not good) in self-perceived health status by more than $20 \%$ of the respondents over the 19 year period $(1994-2013)$. This period registered a rise in diagnosed chronic disease by the respondents. During the same period affluence level (proxied by the ownership of the assets and savings by the household) and living condition (proxied by the access to the public service utilities) exhibited a positive movement amongst the respondents. The inflation adjusted adult equivalent household income (mean) increased by more than $85 \%$ amongst the respondents from 1994 to 2013. The Gini index for the study sample changed from 0.272 in 1994 to 0.382 in 2013. But overall satisfaction in life increased by 2.3 times amongst the respondents of this study during the 19 years (1994 to 2013).

Table 2 presents the selection of study sample from RLMS - 1994 datasets. We found that study sample was a representation of more female respondents with relatively smaller household income and less house owners. There was no statistically significant difference in the self-perceived health status between the study sample and RLMS - 1994 datasets when other potential selection variables are included in the model. There was no gender - age interaction in the sample selection process.

Table 3 indicated that the non-standardized perceived health gets worse over time, as one can expect. However, in our sample, the standardized perceived health improves over time. A predictable trend was observed - the nonstandardized self-perceived health status declined while the standardized self-perceived health status improved over time. The test of significance ( $t$-values) indicated that for the sample population, the standardized self-perceived health status from 2002 onwards and non-standardized self-perceived health status from 2006 onwards remained same as was in 2013.

CI was positive for non - standardized and standardized self-perceived health status for all the years (Table 4). The difference in absolute size between CI for non - standardized and that of standardized selfperceived health status was 0.149 in 1994 and 0.06 in 2013 i.e., a reduction of almost $60 \%$ over the 19 year period. The annualized average of this difference was 0.052. A smaller standardized variant of CIs implied that
Table 2 Logit model explaining sample [ $N=1496$ selection from RLMS datasets - 1994 [N=8893]*

\begin{tabular}{ll}
\hline Variables & Coefficient \\
\hline Self-perceived health (Comparison group: Very good) & \\
Good & 0.47 \\
Average & 0.72 \\
Bad & 0.29 \\
Very bad & 0.28 \\
Age & -0.01 \\
Gender & $0.78^{* *}$ \\
Age* Female (interaction term ${ }^{\text {a }}$ & 0.00 \\
Diagnosed chronic disease & $-0.44^{*}$ \\
Geography of residence (1 = urban) & $-0.30^{*}$ \\
Overall satisfaction with life (1 = satisfied) & -0.12 \\
Adult equivalent household income & $-0.07^{* * *}$ \\
Ownership of assets & \\
Tractor (1 = yes) & 0.27 \\
Motor vehicle (1 =yes) & 0.03 \\
Country house (1 = yes) & -0.16 \\
House (1 = yes) & $-0.38^{* *}$ \\
Additional apartment (1 = yes) & -0.16 \\
Living condition (access to public services utilities) & 0.054 \\
Central heating & \\
Hot water supply & -0.24 \\
Cooking gas & -0.16 \\
Other indicators of economic position & 0.08 \\
\hline
\end{tabular}

legend: ${ }^{*} p<05 ;{ }^{* *} p<0.01 ;{ }^{* * *} p<0.001$

*The dependent variable is equal to 1 if respondents are included in the sample and 0 , otherwise

anteraction term captures gender effect on age

some of the inequalities in self-perceived health status were unavoidable (attributable to the age structure of the sample). Though the CI for both the non - standardized and standardized self-perceived health status changed in every year, such change in absolute size for both the CIs did not follow any definite trend. A relatively smaller standard error for CIs with standardized selfperceived health status suggested that the serial correlation was corrected with the method of indirection standardization - standardization reduced the variations in self-perceived health status. The $t$-values indicated the existence of significant inequalities in self-perceived health status in almost all the years without any definite trend in changes of such inequalities. The weighted 
Table 3 The mean of self-perceived health status $(N=1496)$

\begin{tabular}{|c|c|c|c|c|c|}
\hline Year & $\begin{array}{l}\text { Self-perceived } \\
\text { health status } \\
\text { (mean) }\end{array}$ & $\begin{array}{l}\text { Test of difference } \\
\text { from } 2013, \mathrm{t} \text { - test, } \rho\end{array}$ & $\begin{array}{l}\text { Standardized self- } \\
\text { perceived health status } \\
\text { (mean) }\end{array}$ & $\begin{array}{l}\text { Test of difference } \\
\text { from } 2013, t \text { - test, } \rho\end{array}$ & $\begin{array}{l}\text { Difference in mean (standardized - non- } \\
\text { standardized) self-perceived health status }\end{array}$ \\
\hline 1994 & 2.88 & 0.000 & 3.06 & 0.000 & 0.18 \\
\hline 1995 & 2.84 & 0.000 & 3.01 & 0.000 & 0.17 \\
\hline 1996 & 2.84 & 0.000 & 2.99 & 0.005 & 0.15 \\
\hline 1998 & 2.86 & 0.000 & 2.98 & 0.019 & 0.12 \\
\hline 2000 & 2.90 & 0.000 & 2.97 & 0.033 & 0.07 \\
\hline 2001 & 2.93 & 0.00 & 2.98 & 0.016 & 0.05 \\
\hline 2002 & 2.92 & 0.01 & 2.96 & 0.136 & 0.03 \\
\hline 2003 & 2.95 & 0.032 & 2.97 & 0.055 & 0.02 \\
\hline 2004 & 2.93 & 0.006 & 2.94 & 0.589 & 0.00 \\
\hline 2005 & 2.96 & 0.010 & 2.93 & 0.625 & -0.02 \\
\hline 2006 & 3.01 & 0.961 & 2.97 & 0.025 & -0.04 \\
\hline 2007 & 2.99 & 0.108 & 2.93 & 0.635 & -0.06 \\
\hline 2008 & 3.00 & 0.017 & 2.93 & 0.872 & -0.07 \\
\hline 2009 & 3.02 & 0.659 & 2.93 & 0.689 & -0.09 \\
\hline 2010 & 3.03 & 0.387 & 2.91 & 0.463 & -0.12 \\
\hline 2011 & 3.05 & 0.168 & 2.91 & 0.502 & -0.14 \\
\hline 2012 & 3.04 & 0.530 & 2.89 & 0.110 & -0.16 \\
\hline 2013 & 3.10 & Comparison year & 2.92 & Comparison year & -0.17 \\
\hline Average & 2.96 & & 2.95 & & -0.01 \\
\hline
\end{tabular}

average of self-perceived health status $[I(v)]$ was equal to CI when $v$ was equal to 2; with increased $v$ (increasing weight on the self-perceived health status of the worseoff) disachievement became significantly large enough for all the years. The highest disachievement was in year 2000 .

\section{Discussion}

We followed 1,496 adults over a period of 19 years (1) to investigate the evolution of health differences among Russians in the context of neo-liberal restructuring with welfare-state retrenchment [34], and (2) to examine the distribution of evolved health differences across the socioeconomic strata of the population from 1994 to 2013. Our approach removed the effect of the changing composition of the sample and relied on the inter-individual differences to reduce the collinearity between current and lag variables to estimate unrestricted timeadjustment patterns [35]. Denisova [36] acknowledged potential importance of attrition bias in the study using RLMS datasets of 14 years (1994 - 2007) while concluding that the effect of such attrition bias did not have any significant health differences between those left in the sample and those remained in the sample datasets of RLMS. Further, applying inverse probability weighting (IPW) estimation method [37] on RLMS datasets (2001 - 2010), Gerry and Papadopoulos [38] have established that self-perceived health $(\mathrm{SAH})$ related attrition in the longitudinal elements of RLMS surveys do not have the effect on the model results.

In spite of this fact, the individuals in the sample are getting older, and our results indicated a systematic trend of improvement, though not consistent, in the age-, gender-, and diagnosed chronic diseases-standardized mean of the self-perceived health status after controlling for the effect of region, settlement of residence (urban or rural), and SES for the study population. The standardized mean selfperceived health status registered an overall positive shift of $4.60 \%$ from 1994 to 2013. During this period (19942013), the Gini index - a measure of distributional equality $(0=$ perfect equality; 1 = absolute inequality) of material affluence - became positive by $40.44 \%$. Our results also supported the evidence from Gerry and Papadopoulos [38] who had showed that there was a significant unobserved individual heterogeneity associated with age and with initial self-perceived health status in the RLMS datasets $(2001-2010)$.

We could not find any obvious effect of the macroeconomic crisis (1998) on the self-perceived health status within our study cohort. Though inequality indices (the concentration index; a bivariate measure of inequality, measuring inequality in self-perceived health status related to the ranking of the individual within SES) in the distribution of good self-perceived health status (non- 
Table 4 Levels of and inequalities* of self-perceived health status

\begin{tabular}{|c|c|c|c|c|c|c|c|}
\hline \multirow[b]{3}{*}{ Year } & \multicolumn{2}{|c|}{ Self-pereceived health } & \multicolumn{5}{|c|}{ Self-pereceived health - standardized } \\
\hline & & & & & $v=2$ & $v=3$ & $v=5$ \\
\hline & ${ }^{a}$ C.I. [S.E.] & $\overline{c_{t-t e s t}(C l)}$ & ${ }^{\mathrm{b}}$ C.I. [S.E.] & $c_{t \text {-test }}(\mathrm{Cl})$ & $I(V)[S . E]$. & $I(v)[S . E]$. & I(V) [S.E.] \\
\hline 2013 & $0.112(0.034)$ & 3.29 & $0.052(0.019)$ & 2.74 & $0.052(0.019)$ & $0.072(0.028)$ & $0.133(0.041)$ \\
\hline 2012 & $0.153(0.032)$ & 4.78 & $0.043(0.020)$ & 2.15 & $0.043(0.020)$ & $0.068(0.030)$ & $0.149(0.042)$ \\
\hline 2011 & $0.047(0.031)$ & 1.52 & $0.061(0.019)$ & 3.21 & $0.061(0.019)$ & $0.091(0.030)$ & $0.167(0.041)$ \\
\hline 2010 & $0.071(0.031)$ & 2.29 & $0.067(0.018)$ & 3.72 & $0.067(0.018)$ & $0.107(0.030)$ & $0.198(0.040)$ \\
\hline 2009 & $0.090(0.032)$ & 2.81 & $0.067(0.017)$ & 3.94 & $0.067(0.017)$ & $0.104(0.026)$ & $0.187(0.038)$ \\
\hline 2008 & $0.136(0.031)$ & 4.39 & $0.072(0.018)$ & 4.00 & $0.072(0.018)$ & $0.118(0.027)$ & $0.221(0.039)$ \\
\hline 2007 & $0.131(0.030)$ & 4.37 & $0.065(0.017)$ & 3.82 & $0.065(0.017)$ & $0.101(0.026)$ & $0.190(0.038)$ \\
\hline 2006 & $0.144(0.035)$ & 4.11 & $0.059(0.017)$ & 3.47 & $0.059(0.017)$ & $0.104(0.025)$ & $0.212(0.036)$ \\
\hline 2005 & $0.108(0.031)$ & 3.48 & $0.086(0.018)$ & 4.78 & $0.086(0.018)$ & $0.133(0.027)$ & $0.241(0.038)$ \\
\hline 2004 & $0.125(0.030)$ & 4.17 & $0.053(0.017)$ & 3.12 & $0.053(0.017)$ & $0.08(0.027)$ & $0.157(0.038)$ \\
\hline 2003 & $0.092(0.029)$ & 3.17 & $0.052(0.017)$ & 3.06 & $0.052(0.017)$ & $0.070(0.027)$ & $0.126(0.039)$ \\
\hline 2002 & $0.065(0.029)$ & 2.24 & $0.067(0.017)$ & 3.94 & $0.067(0.017)$ & $0.106(0.026)$ & $0.199(0.038)$ \\
\hline 2001 & $0.107(0.028)$ & 3.82 & $0.071(0.018)$ & 3.94 & $0.071(0.018)$ & $0.102(0.027)$ & $0.186(0.038)$ \\
\hline 2000 & $0.153(0.034)$ & 4.50 & $0.101(0.022)$ & 4.59 & $0.101(0.022)$ & $0.151(0.033)$ & $0.262(0.046)$ \\
\hline 1998 & $0.159(0.032)$ & 4.97 & $0.072(0.021)$ & 3.43 & $0.072(0.021)$ & $0.104(0.033)$ & $0.180(0.049)$ \\
\hline 1996 & $0.135(0.032)$ & 4.22 & $0.068(0.022)$ & 3.09 & $0.068(0.022)$ & $0.083(0.033)$ & $0.133(0.049)$ \\
\hline 1995 & $0.112(0.033)$ & 3.39 & $0.099(0.020)$ & 4.95 & $0.099(0.020)$ & $0.144(0.032)$ & $0.230(0.046)$ \\
\hline 1994 & $0.201(0.035)$ & 5.74 & $0.052(0.020)$ & 2.60 & $0.052(0.019)$ & $0.072(0.029)$ & $0.130(0.043)$ \\
\hline Average & $0.119(0.032)$ & & $0.067(0.019)$ & & $0.067(0.019)$ & $0.101(0.029)$ & $0.183(0.041)$ \\
\hline
\end{tabular}

${ }^{a}$ for self-perceived health status (non-standardized)

${ }^{b_{\text {for }}}$ self-perceived health status (standardized)

ccalculated from the indices and standard error [47]

S.E. = standard error (with bootstrapped)

*All estimates are significant at $p<0.001$

standardized) became smaller in 2013 compared to 1994 (a year that was economically weak for Russians) - suggesting a concentration of the good self-perceived health status (non-standardized) in the worse-off SES quintile in 2013 - no systematic trend emerges in the time path of concentration indices over almost two decades (1994-2013). The highest value of the disachievement index of year 2000 might be attributed to the macroeconomic effect of the 1998 economic crisis on standardized self-perceived health status of the study population.

This absence of consistent time trend is largely consistent with a similar phenomenon found in previous research [14] using Swiss survey datasets. A same absolute size of CI for standardized self-perceived health status in 1994, 2003, 2004 and 2013 indicated a uniform effect of age, gender and diagnosed chronic diseases on the selfperceived health status of the study population when effect of the confounding variables i.e., region, settlement of residence, and SES were controlled. Average effect of these standardising variables on the self-perceived health status of the study population was found to be more than $40 \%$ but without any consistent trend on year-onyear. Perhaps a phenomenon like this can be explained by the pathways [10] from socioeconomic strata to health that have shaped individual responses to selfperceived health status. In addition, changes in concentration indices can be decoded as the expressions of macroeconomic factors on happiness (fluctuations in negative affect) when the economy is still dynamic, open and volatile [12]. Further, such a phenomenon also reflects life course variation in the SES gradient in health $[39,40]$.

Concerning the extent to which the inequality in good self-perceived health status varies with position of the individual in SES quintile, we found evidence that the variations of good self-perceived health status (both standardized and non-standardized) was not uniform within study population across. We found evidence that the better-off enjoys good self-perceived health status in all the years. Though the absolute size of CI for non standardized self-perceived health status was reduced by 44.27 \% from 1994 to 2013 , there was not much change in the distribution of study population across SES quintiles in these two years but overall satisfaction with life for the study population became more than doubled from 1994 to 2013. Further, inequalities (difference 
between the CIs of non-standardized and standardized self-perceived health status) in self-perceived health status for the sample population was reduced by almost $60 \%$ over the 19 year period. This reflection of positive shift of good health for the worse-off was consistent with plausible theoretical and empirical findings that the selfperceived health status of the individual is related to subjective rank perceptions of the individual with the SES [41-44], in other words, subjective socioeconomic status $(\mathrm{SSS})^{7}$ rather than SES relates better to the selfperceived health status of the individual.

Marchand et al. [45] argues that any health gains among the better-off in the course of implementing efforts to improve the health of the worse-off is a positive externality because of the dilution in inequality reduction. Such argument translates to a policy that resulted in the same proportional improvement in everyone's health would raise the value of the distributionallysensitive measure of population health, while a policy that led to the same increase in the mean but a larger (smaller) proportional improvement in the health of the poor would produce a larger (smaller) increase in it. The mean self-perceived health status weighs everyone's health equally, so, we estimated degree of aversion [33] to self-perceived health differences between the worseoff and the better-off within the study population. With the weights attached to the standardized self-perceived health status of the worse off ( $v=3$ and $v=5$ ), we found disachievement $(I(v))$ was becoming larger and larger, indicating that the values of the achievement index are sensitive to the weight set on the health of the worse-off population.

\section{Conclusion}

An orientation towards inequity demands reduction of health status difference between worse-off (disadvantaged) and the better-off. The significance of measuring health inequality becomes a policy relevant tool if we can identify the aversion to inequality. The Gini coefficient, a general measure of the distribution of wealth, often does not correlate with the measure of health inequality (concentration index) in a transitional economy that lacks predictability. Furthermore, subjective socioeconomic status (SSS), proxied by overall satisfaction with life has emerged as an important determinant that correlates better with self-perceived health status. SSS, the rank-based facets of SES, shapes the revealed health status for the Russian Federation. We consider our results fairly robust, since we find the presence of diagnosed chronic disease risks in the respondents with bad and very bad self-perceived health.

This study contributes by exploring the evolution of differences in self-perceived health in the transition from a welfare regime to a market-driven open economy. We analysed the recent survey datasets to capture the changes and the distribution in self-perceived adult health status in different socioeconomic stages of life course. This panel study, which has followed the adult respondents for a long period (1994-2013), provides empirical evidence in subscribing to the fact that (1) the in-country average of self-perceived health status is not sufficient enough to guide policy action in reducing health inequalities, and (2) the socioeconomic strataspecific mean and the distribution of self-perceived health status within socioeconomic strata are important guides to improve the average health of the population.

Despite unfolding self-perceived health status gradient of selected individuals over 19 year period, the study sample selection and size of the study sample limits the generalisability of the study findings for the entire Russian population. RLMS is a nationally representative instrument with a multistage stratified sample, but the size of our cohort restricts the full representation of the entire country. The selection can have an impact on the association between neighbourhood factors and selfperceived health status. Though our measure of collective efficacy $^{8}$ is purged of its association with individual-level social support and sociability, the datasets do not allow individual-level control to be derived directly from RLMS.

Our finding that differences in the distribution of self-perceived health cannot be explained by the socioeconomic strata position of the individual suggests that future research should take into account the context of stated self-perceived health status in the realm of subjective socioeconomic status (SSS), i.e., the individual's subjective perceptions of their position relative to others in the socioeconomic hierarchy of the neighbourhood.

\section{Endnotes}

${ }^{1}$ Because of the decline in response rate in big cities, the proportion of the big cities in the sample became less than needed and continued to decrease each round, so in Round 15 (2006; http://www.cpc.unc.edu/projects/ rlms-hse/data) sample repair was done. New households were added to reconstruct the share of each region in the sample (to make it equal to that of 1994 sample).

${ }^{2}$ OECD-modified scale. After having used the "old OECD scale" in the 1980s and the earlier 1990s, the Statistical Office of the European Union (EUROSTAT) adopted in the late 1990s the so-called "OECD-modified equivalence scale". This scale, first proposed by Haagenars et al. (1994), assigns a value of 1 to the household head, of 0.5 to each additional adult member and of 0.3 to each child.

${ }^{3} G=\frac{2 \operatorname{covar}\left(y, r_{y}\right)}{N \bar{y}}$, where $\operatorname{covar}\left(y, r_{y}\right)$ is the covariance between income $(y)$ and ranks of all households according to the income $\left(r_{y}\right)$ ranging from the poorest 
household (rank $=1)$ to the richest $(\operatorname{rank}=\mathrm{N}) . \mathrm{N}$ is the total number of households, and $\bar{y}$ is the mean of the adult equivalent household income (YitzhakI, 1994 and Lerman \& Yitzhaki, 1984).

${ }^{4}$ Indirectly standardised health is the difference between observed and expected health where expected health for an individual is the average health of individuals with the same levels of the standardising variables as the individual. With groups, expected health for an SES group is the weighted average of health levels conditional on the standardising variables, where the weights are the proportion of the SES group population in the sub groups defined by the standardising variables.

${ }^{5} \mathrm{~A}$ regression method that corrects for heteroscedasticity and autocorrelation.

${ }^{6}$ Defined as a weighted average of the self-perceived health status of the respondents where higher weights are attached to poorer people. It reflects the average level of self-perceived health status and the inequality in health (expressed as self-perceived health status) between the worse-off and the better-off.

${ }^{7}$ Subjective socioeconomic status (SSS) is defined as a person's subjective perceptions of their rank, relative to others, in the socioeconomic hierarchy (Kraus, Piff, \& Keltner, 2011, 2009; Singh-Manoux, Adler, \& Marmot, 2003 and Adler, Epel, Castellazo, \& Ickovics, 2000).

${ }^{8}$ Emphasizes mutual trust and solidarity (social cohesion), and shared expectations for pro-social action (informal social control) in theorizing the impact of neighborhood social organization on local residents' well-being. Evidence suggests that collective efficacy is a generalizable resource capable of influencing a wide range of outcomes, including self-perceived (self-perceived) health status (Browning \& Cagney, 2002).

\section{Appendix - A}

The concentration curve plots the cumulative proportion of self-perceived health (y) against the cumulative share of the population ranked by SES variables. The curve lies below the $45^{\circ}$ line (diagonal) of equality if selfperceived health is concentrated among the better-off and above the $45^{\circ}$ line (diagonal) of equality if selfperceived health is concentrated among the worse-off. The $\mathrm{CI}$ is defined as twice the area between the concentration curve and the diagonal (the line of equality).

$C I=\frac{2}{n \mu} \sum_{i=1}^{n} y_{i} R_{i}-1, \mathrm{n}$ is the sample size and $\mathrm{R}$ denotes the individual's fractional rank (position of the individual) in the SES distribution. $\mu$, the mean of the binary variable $y$ (self-perceived health status) whose distribution across SES is the subject of interest. For, $\mu>0$ (if $y=0$ for all $i$, CI is undefined) the minimum value of $\mathrm{CI}$ is equal to, $\mu-1+\left(\frac{1}{n}\right)$, and the maximum value is equal to $1-\mu+\left(\frac{1}{n}\right)$.
For a given, $\mu>0$, the maximum of the $\mathrm{CI}$ is when the poorest $j$ individuals have a value of $y$ equal to zero, and the richest $n-j$ individuals have a value of $y$ equal to one.

Therefore, $\mu=\frac{n-j}{n}$ and $\mathrm{CI}=1-\mu+\frac{1}{n}$. For the large samples, the $\frac{1}{n}$ term vanishes, and the minimum and maximum tend to $\mu-1$ and $1-\mu$ respectively [46].

$$
R_{i}=\sum_{j=1}^{i-1} w_{j}+\frac{1}{2} w_{i} \text {, where } w_{0}=0 . R_{i} \text { denotes the }
$$
weighted cumulative proportion of the population up to the midpoint of each individual weight and is bounded in the $(0 ; 1)$ interval. $R_{i}$ represents the cumulative distribution function of SES and indicates the individual's position within the SES distribution.

We estimated CI from regression of a transformation (correction of the standard error for across SES correlation owing to the rank nature of the regressor) of the self-perceived health status on the fractional rank in SES distribution [47]. Newey-West regression [48], which corrects for autocorrelation as well as heteroscedasticity,

\section{Appendix - B}

Achievement index: $I(v)=\frac{1}{N} \sum_{i=1}^{N} \mathrm{~h}_{i} v\left(1-R_{i}\right)^{v-1}$ where,

- $h$ is a measure of standardized self-perceived health (the high value of $I(v)$ is to be considered as good)

- $v=$ inequality aversion parameter; if, $v=1$, everyone's health is weighted equally; as, $v$ is raised above 1, the weight attached to the health of a very poor person rises

- $R_{i}=$ fractional rank of the individual; so, the weight attached to the $i^{\text {th }}$ person's health share is, $v\left(1-R_{i}\right)^{v-1}$.

Hence, the achievement index captures inequality in the distribution of health and is deduced to

$$
\begin{aligned}
& I(v)=\mu(1-C(v)), \\
& {\left[C(v)=-\frac{v}{\mu} \operatorname{cov}\left\langle h_{i},\left(1-R_{i}\right)^{v-1}\right\rangle\right]}
\end{aligned}
$$

If standardized self-perceived health declines monotonically with SES, the greater the degree of inequality aversion, the greater the wedge between the mean $\mu$ and the value of the index $I(v)$.

\section{Competing interests}

The authors declare they have no competing interests.

\section{Authors' contributions}

PP has carried out the analysis of the datasets and drafted the manuscript. $\mathrm{HV}$ and PP interpreted the analysis. HV finally edited the manuscript. Both authors have read and approved the final manuscript. 


\section{Acknowledgements}

The authors wish to express their deepest gratitude to Donna Miles, Senior Programmer, and Klara Peter, Associate Professor, Carolina Population Center, University of North Carolina, Chapel Hill, NC 27516, for making the Russian Longitudinal Monitoring Survey (RLMS) datasets available for this study and also for providing constant support in managing the RLMS datasets used in this study.

Received: 13 August 2015 Accepted: 17 February 2016

Published online: 29 February 2016

\section{References}

1. Komlos J. On the biological standard of living in Russia and the Soviet Union. Slavic Rev. 1999;58:71-9.

2. Steckel R. Stature and the standard of living. J Econ Lit. 1995;33:1903-40.

3. Preston SH. The Changing Relation Between Mortality and Level of Economic Development. Population Studies. 1975;29(2):231-48.

4. Browning CR, Cagney KA. Moving beyond Poverty: Neighborhood Structure, Social Processes, and Health. J Health Soc Behav. 2003;44(4):552-71.

5. Blázquez M, Cottini E, Herrarte A. Socioeconomic gradient in health: how important is material deprivation? Amsterdam: AIAS, GINI Discussion Paper; 2012. p. 39.

6. Vella V. Health and nutritional aspects of well-being. In: Klugman J, editor. Poverty in Russia: Public Policy and Private Response. Washington, DC: The World Bank; 1997

7. Cockerham WC. Health lifestyles in Russia. Soc Sci Med. 2000:51:1313-24.

8. Cockerham WC, Snead MC, DeWaal DF. Health lifestyles in Russia and the socialist heritage. J Health Soc Behav. 2002;43(1):42-55.

9. Kraus MW, Adler N, Chen TWD. Is the Association of Subjective SES and SelfRated Health Confounded by Negative Mood? An Experimental Approach. Health Psychol. 2013;32(2):138-45. doi:10.1037/a0027343.

10. Ostrove J, Adler NE. Socioeconomic Status and Health: What We Know and What We Don't. In: Adler Nancy E, Marmot M, McEwen Bruce S, Stewart J, editors. Socioeconomic Status and Health in Industrial Nations: Social, Psychological, and Biological Pathways. New York: New York Academy of Sciences; 1999. p. 3-15.

11. Eggers A, Gaddy C, Graham C. Well-being and unemployment in Russia in the 1990s: can society's suffering be individuals' solace? Journal of Socio-Economics. 2006;35:209-42

12. Rodríguez-Pose A, Maslauskaite K. Can policy make us happier? Individual characteristics, socio-economic factors and life satisfaction in Central and Eastern Europe. Cambridge Journal of Regions, Economy and Society. 2012;5:77-96.

13. Hernandez-Quevedo C, Jones AM, Rice N. Persistence in health limitations: a European comparative analysis. University of York: HEDG, Working Paper, \#07/03; 2007.

14. Leu RE and Schellhorn M. The Evolution of Income-Related Health Inequalities in Switzerland over Time. IZA Discussion paper series 2004, No. 1346

15. Krieger N. Epidemiology and the web of causation — has anyone seen the spider? Soc Sci Med. 1994;39(7):887-903.

16. Willson AE, Kim S, Elder Jr GH. Cumulative Advantage Processes as Mechanisms of Inequality in Life Course Health. Am J Sociol. 2007;112(6):1886-924.

17. Blane D. The life course, the Social Gradient and Health. In: Richard W, Michael M, editors. Social Determinants of Health. New York: Oxford University Press; 2006. p. 54-77.

18. Wadsworth MEJ. Health Inequalities in the Life Course perspective. Soc Sci Med. 1997:44:859-69.

19. Gwatkin D. Health inequalities and the health of the poor: what do we know? What can we do? Bull World Health Organ. 2000;78(1):3-17.

20. Wagstaff A. Socioeconomic inequalities in child mortality: comparisons across nine developing countries. Bull World Health Organ. 2000:78:19-29.

21. Makinen $\mathrm{M}$ et al. Inequalities in healthcare use and expenditures: empirical data from eight developing countries and countries in transition. Bull World Health Organ. 2000;78:55-65

22. Castro-Leal F et al. Public spending on healthcare in Africa: do the poor benefit? Bull World Health Organ. 2000;78:66-74.

23. Wooldridge JM. Econometric Analysis of Cross Section and Panel Data. Cambridge: MIT Press; 2002.
24. Adams P, Hurd MD, McFadden D, Merrill A, Ribiero T. Healthy, Wealthy and Wise? Tests for Direct Causal Paths between Health and Socioeco- nomic Status. J Econ. 2003;112:3-56.

25. Frijters $P$, Haisken-DeNew JP, Shields MA. Estimating the causal effect of income on health: evidence from postreunification East Germany. Australian National University: Centre for Economic Policy Discussion Paper No. $465 ; 2003$.

26. Benzeval M, Judge K, Shouls S. Understanding the relationship between income and health: how much can be gleamed from cross-sectional data? Soc Policy Adm. 2001;35(4):376-96.

27. Smith J. Healthy bodies and thick wallets: the dual relation between health and economic status. J Econ Perspect. 1999;13:145-66

28. Schokkaert $E$, van de Voorde C. Risk selection and the specification of the conventional risk adjustment formula. J Health Econ. 2009;28(6):361-74.

29. Gravelle $\mathrm{H}$. Measuring income related inequality in health: standardisation and the partial concentration index. Health Econ. 2001;12(10):803-19.

30. Benyamini Y, Idler EL. Community Studies Reporting Association Between Self- Rated Health and Mortality. Res Aging. 1999;21:477-500.

31. Idler EL, Benyamini Y. Self-Rated Health and Mortality: A Review of TwentySeven Community Studies. J Health Soc Behav. 1997:38:21-37.

32. Wolinsky FD, Tierey WM. Self-rated health and adverse health outcomes: An exploration and refinement of the trajectory hypothesis. Journal of Gerontology: Social Sciences. 1998;53B(6):S336-40.

33. Wagstaff A. Inequality Aversion, Health Inequalities and Health Achievement. J Health Econ. 2002;21(4):627-41.

34. Beckfield J, Krieger N. Epi 1 demos 1 cracy: Linking Political Systems and Priorities to the Magnitude of Health Inequities-Evidence, Gaps, and a Research Agenda. Epidemiol Rev. 2009;31:152-77.

35. Pakes A, Griliches Z. Estimating distributed lags in short panels with an application to the specification of depreciation patterns and capital stock constructs. Rev Econ Stud. 1984:51:243-62.

36. Densinova I. Adult mortality in Russia: A microanalysis. Economics of Transition. 2010:19(2):333-63.

37. Wooldridge JM. Econometric Analysis of Cross Section and Panel Data. Cambridge: MIT Press; 2010.

38. Gerry CJ, Papadopoulos G. Sample attrition in the RLMS, 2001-10. Economics of Transition. 2015:23(2):425-68.

39. Mirowsky J, Ross CE. Education and Self-Rated Health: Cumulative Advantage and Its Rising Importance. Res Aging. 2008:30:93-122.

40. Lynch SM. Cohort and Life-Course Patterns in the Relationship between Education and Health: A Hierarchical Approach. Demography. 2003:40:309-31.

41. Cohen S, Alper CM, Doyle WJ, Adler N, Treanor JJ, Turner RB. Objective and subjective socioeconomic status and susceptibility to the common cold. Health Psychol. 2008;27:268-74. PubMed: 18377146.

42. Singh-Manoux A, Adler NE, Marmot MG. Subjective social status: Its determinants and its associations with measures of ill-health in the Whitehall II study. Soc Sci Med. 2003;56:1321-33. PubMed: 12600368.

43. Goodman E, Adler NE, Kawachi I, Frazier AL, Huang B, Colditz GA. Adolescents' perceptions of social status: Development and evaluation of a new indicator. Pediatrics. 2001:108:1-8. PubMed:11433046.

44. Adler NE, Epel ES, Castellazzo G, Ickovics JR. Relationship of subjective and objective social class with psychological functioning: preliminary data in healthy White women. Health Psychol. 2000;19:586-92. PubMed: 11129362.

45. Marchand S, Wikler D, Landesman B. Class, health, and justice: health and society. Milbank Memorial Fund Quarterly. 1998:76:449-67.

46. Wagstaff $\mathrm{A}$. The bounds of the concentration index when variable of interest is binary, with an application to immunization inequality. Health Econ. 2005;14:429-32.

47. Kakwani NC, Wagstaff A, van Doorslaer E. Socioeconomic Inequalities in Health: Measurement, Computation and Statistical Inference. Journal of Econometric. 1997:s77(1):87-103.

48. Newey WK, West KD. Automatic Lag Selection in Covariance Matrix Estimation. Rev Econ Stud. 1994;61(4):631-53. 